\title{
PENGARUH RELAKSASI NAPAS DALAM DENGAN AROMATERAPI LAVENDER TERHADAP TINGKAT NYERI POST APENDIKTOMI DI RUANG JANGER RSD MANGUSADA
}

\author{
I Gusti Ayu Dewi Indra Lestari', I Made Dwie Pradnya Susila ${ }^{2}$, A.A. Ngurah Nara Kusuma ${ }^{3}$ \\ STIKES Bina Usada Bali ${ }^{123}$ \\ e-mail:2dwiepradnya@gmail.com
}

\begin{abstract}
Appendectomy is a surgical procedure for appendicitis. This action can cause the perception of pain so that it has an impact on the healing process and triggers further complications if left untreated. Deep breathing relaxation techniques combined with aromatherapy is one of the treatments done to help overcome post appendectomy pain. This study purposed to determine the effect of deep breath relaxation with lavender aromatherapy on the level of post appendectomy pain in the Janger Room RSD Mangusada. This study is a pre-experimental research with one group pretest and posttest design involving 32 samples selected through purposive sampling technique. Collecting data using a research instrument in the form of the Numerical Rating Scale observation sheet. The results showed that there was an effect of deep breath relaxation with lavender aromatherapy on the level of post appendectomy pain in the Janger Room at RSD Mangusada ( $p$-value =0,000). This research can be applied in the provision of nursing services as one of the nursing interventions to reduce post appendectomy patient pain.
\end{abstract}

Keywords: lavender aromatherapy, deep breath relaxation, pain

\begin{abstract}
ABSTRAK
Apendiktomi adalah prosedur pembedahan untuk radang usus buntu. Tindakan ini dapat menimbulkan persepsi nyeri sehingga berdampak pada proses penyembuhan dan memicu komplikasi lebih lanjut jika tidak ditangani. Teknik relaksasi nafas dalam yang dipadukan dengan aromaterapi merupakan salah satu perawatan yang dilakukan untuk membantu mengatasi nyeri pasca operasi usus buntu. Penelitian ini bertujuan untuk mengetahui pengaruh relaksasi nafas dalam dengan aromaterapi lavender terhadap tingkat nyeri post apendektomi di Ruang Janger RSD Mangusada. Penelitian ini merupakan penelitian pra-eksperimen dengan rancangan one group pretest and posttest design yang melibatkan 32 sampel yang dipilih melalui teknik purposive sampling. Pengumpulan data menggunakan instrumen penelitian berupa lembar observasi Numerical Rating Scale. Hasil penelitian menunjukkan bahwa ada pengaruh relaksasi nafas dalam dengan aromaterapi lavender terhadap tingkat nyeri post apendektomi di Ruang Janger RSD Mangusada ( $\mathrm{p}$-value $=0,000$ ). Penelitian ini dapat diterapkan dalam pemberian pelayanan keperawatan sebagai salah satu intervensi keperawatan untuk mengurangi nyeri pasien post apendiktomi.
\end{abstract}

Kata kunci: aromaterapi Lavender, relaksasi nafas dalam, nyeri

\section{PENDAHULUAN}

Kejadian apendisitis menjadi salah satu jenis kasus keadaan darurat bedah yang banyak terjadi dan juga merupakan salah satu penyebab paling umum dari sakit perut (Craig, 2018). Apendisitis terjadi pada 147 negara dengan jumlah kasus sebanyak 237.961074 kasus (World Health Organization, 2018). Data terakhir mengenai apendisitis di Indonesia didapatkan bahwa terdapat 596.132 orang $(3,36 \%)$ dilaporkan menderita apendisitis pada tahun 2009 dan meningkat menjadi 621.435 orang (3,53\%) pada tahun 2010 (Kementerian Kesehatan Republik Indonesia, 2010). Jumlah insiden apendisitis di Bali sendiri didapatkan bahwa terdapat 1617 kasus apendisitis dan menjadi peringkat keenam dari 10 besar penyakit terbanyak yang dialami pasien rawat inap (Dinas Kesehatan Provinsi Bali, 2017).

Penatalaksanaan apendisitis yang sering dilakukan adalah tindakan pembedahan yang disebut apendiktomi (Noffsinger, 2017). Apendiktomi menyebabkan kerusakan jaringan yang dapat mempengaruhi sensitivitas ujung-ujung saraf dan menstimulus jaringan untuk aktivasi pelepasan zat-zat kimia, hal ini menjadi penyebab munculnya nyeri (Potter \& Perry, 2010). Nyeri menimbulkan dampak buruk seperti terhambatnya proses penyembuhan yang berisiko meningkatkan komplikasi seperti imobilisasi, rehabilitasi dapat tertunda dan hospitalisasi menjadi 
lama, sehingga nyeri pada pasien post operasi harus menjadi prioritas perawatan (Potter \& Perry, 2010).

Nyeri dapat diatasi dengan penatalaksanaan secara farmakologi menggunakan obat-obatan analgetik (Abbasi, 2015; Akhlaghi et al., 2011) dan secara nonfarmakologi salah satunya relaksasi dan aromaterapi (Potter \& Perry, 2010). Terdapat beberapa jenis aromaterapi yang dapat digunakan, salah satunya aromaterapi lavender yang diyakini memiliki sifat antikonvulsan, antidepresi, anxiolytic dan bersifat menenangkan (Koensoemardiyah dalam Widayani, 2017).

Penelitian terdahulu mengungkapkan bahwa terdapat pengaruh teknik relaksasi napas dalam terhadap penurunan intensitas nyeri post section caesarea di RSUD Cianjur $(\mathrm{p}=0,000) \quad$ (Indriati, Triwidiyantari, \& Apriyanti, 2018). Penelitian lainnya juga menyatakan bahwa pemberian lavender efektif dalam menurunkan skala nyeri post sectio caesarea dengan p-value $0,009 \quad(\mathrm{p}<0,05) \quad$ (Rahmawati \& Rohmayanti, 2015).

Peneliti telah melakukan studi pendahuluan didapatkan bahwa apendisitis menjadi salah satu dari 10 besar penyakit rawat inap terbanyak, dengan persentase sebesar $8,73 \%$. Peneliti telah melakukan wawancara pada 7 pasien post operasi apendiktomi dan didapatkan bahwa seluruhnya (100\%) mengalami nyeri pada abdomen yang dilakukan insisi saat operasi.

Berdasarkan uraian diatas, peneliti tertarik untuk melakukan penelitian yang bertujuan untuk mengetahui pengaruh relaksasi napas dalam dengan aromaterapi lavender terhadap tingkat nyeri pasien post apendiktomi di Ruang Janger RSD Mangusada.

\section{METODE}

Penelitian ini adalah penelitian kuantitatif menggunakan rancangan Pre-Experiment dengan one group pretest and posttest design. Sampel dipilih sebanyak 32 pasien post apendiktomi yang dirawat di Ruang Janger RSD Mangusada melalui teknik Purposive Sampling menggunakan kriteria inklusi dan eksklusi. Pengumpulan data menggunakan instrumen penelitian berupa lembar observasi Numerical Rating Scale. Data dianalisis menggunakan analisis Wilcoxon.
HASIL

\section{Karakteristik Responden Berdasarkan Usia Tabel 1}

Karakteristik Responden Berdasarkan Usia

\begin{tabular}{lcc}
\hline Usia & $\mathbf{f}$ & $\mathbf{\%}$ \\
\hline 17-25 Tahun & 17 & 53,1 \\
26-35 Tahun & 8 & 25,0 \\
36-45 Tahun & 1 & 3,1 \\
46-55 Tahun & 4 & 12,5 \\
56-65 Tahun & 1 & 3,1 \\
>65 Tahun & 1 & 3,1 \\
\hline Total & $\mathbf{3 2}$ & $\mathbf{1 0 0}$ \\
\hline
\end{tabular}

Tabel di atas menunjukkan bahwa dari 32 responden yang diteliti sebagian besar berusia dalam rentang 1725 tahun, yaitu sebanyak 17 orang $(53,1 \%)$.

\section{Karakteristik Responden Berdasarkan Jenis Kelamin}

Tabel 2

Karakteristik Responden Berdasarkan Jenis Kelamin

\begin{tabular}{ccc}
\hline Jenis Kelamin & f & \% \\
\hline Laki - Laki & 12 & 37,5 \\
Perempuan & 20 & 62,5 \\
\hline Total & $\mathbf{3 2}$ & $\mathbf{1 0 0}$
\end{tabular}

Tabel diatas menunjukkan bahwa menunjukkan bahwa dari 32 responden yang diteliti sebagian besar adalah perempuan yaitu sebanyak 20 orang $(62,5 \%)$.

\section{Karakteristik Responden Berdasarkan Status Perawatan}

Tabel 3

Karakteristik Responden Berdasarkan Status Perawatan

\begin{tabular}{ccc}
\hline Status Perawatan & f & \% \\
\hline Post Appendiktomi Hari 1 & 22 & 68,8 \\
Post Appendiktomi Hari 2 & 10 & 31,3 \\
\hline Total & $\mathbf{3 2}$ & $\mathbf{1 0 0}$ \\
\hline
\end{tabular}

Tabel diatas menunjukkan bahwa dari 32 responden yang diteliti sebagian besar status perawatan dalam kategori post appendiktomi hari 1, yaitu sebanyak 22 orang $(68,8 \%)$ 


\section{Vol. 16 No.2 Mei - Agustus 2021}

Tingkat Nyeri Post Apendiktomi Sebelum Diberikan Relaksasi Napas Dalam dengan Aromaterapi Lavender di Ruang Janger RSD Mangusada

Tabel 4

Tingkat Nyeri Post Apendiktomi Sebelum Diberikan Relaksasi Napas Dalam dengan Aromaterapi Lavender

\begin{tabular}{cccccc}
\hline $\begin{array}{c}\text { Tingkat } \\
\text { Nyeri }\end{array}$ & $\mathbf{N}$ & Min & Max & Mean & $\begin{array}{c}\text { Std. } \\
\text { Deviation }\end{array}$ \\
\cline { 2 - 6 } & 32 & 5 & 8 & 7,09 & 0,928 \\
\hline
\end{tabular}

Tabel diatas menunjukkan bahwa sebelum diberikan relaksasi napas dalam dengan aromaterapi lavender, rata-rata responden mengalami nyeri skala 7 (nyeri berat).

Adapun frekuensi dan distribusi tingkat nyeri post apendiktomi sebelum diberikan relaksasi napas dalam dengan aromaterapi lavender berdasarkan kategori nyeri dapat dilihat pada tabel berikut: Tabel 5

Tingkat Nyeri Post Apendiktomi Sebelum Diberikan Relaksasi Napas Dalam dengan Aromaterapi Lavender di Ruang Janger RSD Mangusada Berdasarkan Kategori Nyeri

\begin{tabular}{lcc}
\hline Tingkat Nyeri & f & \% \\
\hline Tidak nyeri & 0 & 0 \\
Nyeri ringan & 0 & 0 \\
Nyeri Sedang & 7 & 21,9 \\
Nyeri Berat & 25 & 78,1 \\
\hline \multicolumn{1}{c}{ Total } & $\mathbf{3 2}$ & $\mathbf{1 0 0}$ \\
\hline
\end{tabular}

Tabel di atas menunjukkan bahwa sebelum diberikan relaksasi napas dalam dengan aromaterapi lavender, tingkat nyeri responden lebih banyak berada dalam kategori nyeri berat, yaitu sebanyak 25 orang $(78,1 \%)$.

Tingkat Nyeri Post Apendiktomi Sesudah Diberikan Relaksasi Napas Dalam dengan Aromaterapi Lavender di Ruang Janger RSD Mangusada

Tabel 6

Tingkat Nyeri Post Apendiktomi Sesudah Diberikan Relaksasi Napas Dalam dengan Aromaterapi Lavender

\begin{tabular}{cccccc}
\multicolumn{6}{c}{ Lavender } \\
$\begin{array}{c}\text { Tingkat } \\
\text { Nyeri }\end{array}$ & $\mathbf{N}$ & Min & Max & Mean & $\begin{array}{c}\text { Std. } \\
\text { Deviation }\end{array}$ \\
\cline { 2 - 6 } & 32 & 3 & 7 & 5,53 & 1,218 \\
\hline
\end{tabular}

Tabel diatas menunjukkan bahwa sesudah diberikan relaksasi napas dalam dengan aromaterapi lavender, rata-rata responden mengalami nyeri dengan skala 5 (nyeri sedang).

Adapun frekuensi dan distribusi tingkat nyeri post apendiktomi sesudah diberikan relaksasi napas dalam dengan aromaterapi lavender di Ruang Janger RSD
Mangusada berdasarkan kategori nyeri dapat dilihat pada tabel berikut:

Tabel 7

Tingkat Nyeri Post Apendiktomi Sesudah Diberikan Relaksasi Napas Dalam dengan Aromaterapi Lavender di Ruang Janger RSD Mangusada Berdasarkan Kategori Nyeri

\begin{tabular}{lcc}
\hline Tingkat Nyeri & f & \% \\
\hline Tidak nyeri & 0 & 0 \\
Nyeri ringan & 1 & 3,1 \\
Nyeri Sedang & 22 & 68,8 \\
Nyeri Berat & 9 & 28,1 \\
\hline Total & $\mathbf{3 2}$ & $\mathbf{1 0 0}$ \\
\hline
\end{tabular}

Tabel di atas menunjukkan menunjukkan bahwa sesudah diberikan relaksasi napas dalam dengan aromaterapi lavender, tingkat nyeri responden lebih banyak berada dalam kategori nyeri sedang, yaitu sebanyak 22 orang $(68,8 \%)$.

Pengaruh Relaksasi Napas Dalam Dengan Aromaterapi Lavender Terhadap Tingkat Nyeri Post Apendiktomi di Ruang Janger RSD Mangusada

Tabel 8

Pengaruh Relaksasi Napas Dalam Dengan Aromaterapi Lavender Terhadap Tingkat Nyeri Post Apendiktomi di Ruang Janger RSD Mangusada

\begin{tabular}{lcccc}
\hline & Pre & Post & p-value & Z Score \\
\hline Mean & 7,09 & 5,53 & & \\
Max & 8 & 7 & 0,000 & $-4,983$ \\
Min & 5 & 3 & & \\
\hline
\end{tabular}

Berdasarkan hasil analisis dengan uji Wilcoxon didapatkan nilai $p$-value $=0,000(\mathrm{p}<0,05)$ dan $\mathrm{Z}_{\text {Score }}=$ $4,983\left(>Z_{\text {tabel }} \pm 1,96\right)$ yang menunjukkan Ho penelitian ditolak berarti ada pengaruh relaksasi napas dalam dengan aromaterapi lavender terhadap tingkat nyeri post apendiktomi di Ruang Janger RSD Mangusada.

\section{PEMBAHASAN}

Teknik relaksasi napas dalam mampu merangsang tubuh untuk melepaskan hormon endorphin yang merupakan substansi sejenis morfin yang berfungsi sebagai penghambat transmisi impuls nyeri ke otak, sehingga pada saat neuron nyeri mengirimkan sinyal ke otak terjadi sinapsis antara neuron perifer dan neuron yang menuju otak tempat seharusnya subtansi p akan menghasilkan impuls, sehingga endorphin akan memblokir lepasnya substansi p dari neuron sensorik, sehingga sensasi nyeri menjadi berkurang (Aini \& Reskita, 2018). 
Aromaterapi lavender bermanfaat untuk relaksasi, kecemasan dan mood karena adanya peningkatan kekuatan gelombang alpha dan beta yang membuat terjadinya peningkatan relaksasi, juga mampu mendorong aliran energi kreativitas dan perasaan segar dan sehat serta memiliki efek menenangkan, memiliki efek sedasi yang cukup baik dan dapat menurunkan aktivitas motorik mencapai 78\% (Bangun \& Nur'aeni, 2013). Hal ini didukung oleh penelitian terdahulu menyatakan bahwa aromaterapi lavender membantu mengurangi gangguan mood, depresi dan stres (Seifi et al., 2018).

Hasil penelitian ini didukung oleh penelitian terdahulu yang mengungkapkan bahwa ada pengaruh relaksasi napas dalam terhadap intensitas nyeri pada pasien post operatif apendiktomi dengan nilai $\mathrm{p}=0,000$ (Amir \& Nuraeni, 2018). Temuan ini juga sejalan dengan penelitian lain yang mengungkapkan pemberian aromaterapi lavender menurunkan tingkat nyeri pada pasien pasca operasi apendiktomi dengan nilai $p$-value $=0,000$ (Ariany, 2019). Hasil ini juga didukung oleh penelitian sebelumnya yang menyatakan adanya pengaruh yang signifikan menurun pada pemberian aromaterapi lavender dan teknik relaksasi nafas dalam terhadap skala nyeri pada pasien post operasi fraktur ekstremitas dengan nilai $\mathrm{p}=0,000$ (Ghassani \& Firmawati, 2016).

Berdasarkan temuan pada penelitian ini dan pemaparan secara teori diatas, peneliti berasumsi bahwa pemberian relaksasi napas dalam dengan aromaterapi lavender mampu memblok impuls nyeri dalam sistem saraf pusat yang membuat nyeri tidak mampu mencapai reseptor nyeri dan tidak menimbulkan adanya persepsi nyeri yang dirasakan. Pemberian relaksasi napas dalam dengan aromateri lavender juga membuat tubuh mengeluarkan berbagai hormon yang berdampak pada kondisi rileks dan bahagia sehingga nyeri tidak begitu dirasakan lagi.

\section{KESIMPULAN}

Ada pengaruh relaksasi napas dalam dengan aromaterapi lavender terhadap tingkat nyeri post apendiktomi di Ruang Janger RSD Mangusada. Hasil penelitian ini diharapkan dapat diaplikasikan dalam pemberian layanan keperawatan sebagai salah satu intervensi untuk mengurangi tingkat nyeri yang dirasakan pasien post apendiktomi.

\section{DAFTAR PUSTAKA}

1. Abbasi, M. (2015). A comparative study on the concept of convulsion in traditional Iranian medicine and classic medicine. Avicenna Journal of Phytomedicine.

2. Aini, L., \& Reskita, R. (2018). Pengaruh Teknik Relaksasi Nafas Dalam terhadap Penurunan Nyeri pada Pasein Fraktur. Jurnal Kesehatan, 9(2), 262.
3. Akhlaghi, M., Shabanian, G., Rafieian-Kopaei, M., Parvin, N., Saadat, M., \& Akhlaghi, M. (2011). Citrus aurantium Blossom and Preoperative Anxiety. Brazilian Journal of Anesthesiology.

4. Amir, N. D., \& Nuraeni, P. (2018). Pengaruh Teknik Relaksasi Nafas Dalam terhadap Intensitas Nyeri Pada Pasien Post Operatif Appendictomy di Ruang Nyi Ageng Serang RSUD Sekarwangi. Jurnal Keperawatan, 1(2), 107-118.

5. Andarmoyo, S. (2013). Konsep \& Proses Keperawatan Nyeri. Yogyakarta: Ar-Ruzz Media.

6. Annida, R. Z., Utami, F. S., \& Sulistyaningsih. (2019). Efektivitas Pemberian Aromaterapi Lavender Dan Aromaterapi Lemon Terhadap Penurunan Nyeri Persalinan Kala I Fase Aktif Di Klinik Pratama Kusuma Medisca. DSpace UNISA Yogyakarta. Retrieved from http://digilib2.unisayogya.ac.id/handle/123456789 1758

7. Ariany, L. (2019). Pengaruh pemberian aroma terapi lavender terhadap penurunan tingkat nyeri pada pasien pasca operasi Apendiktomi. Jakarta: FK-Usakti.

8. Bangun, A. V., \& Nur'aeni, S. (2013). Pengaruh Aromaterapi Lavender Terhadap Intensitas Nyeri Pada Pasien Pasca Operasi Di Rumah Sakit Dustira Cimahi. Jurnal Keperawatan Soedirman (The Soedirman Journal of Nursing), 8(2), 120-126.

9. Black, J. M., \& Hawks, J. H. (2014). Keperawatan Medikal Bedah Edisi 8 (8th ed.). Jakarta: Elsevier Saunders.

10. Buckle, J. (2014). Clinical aromatherapy: Essential oils in healthcare. In Clinical Aromatherapy: Essential Oils in Healthcare. https://doi.org/10.1016/C20120025781

11. Craig, S. (2018). Appendicitis. Retrieved March 15, 2020, from Medscape website: https://emedicine.medscape.com/article/773895overview

12. Dewi, G. A. A. C. M. (2018). Pengaruh Teknik Relaksasi Nafas Dalam Dengan Menggunakan Aromaterapi Lavender Terhadap Intensitas Nyeri Pasien Post Appendectomy Di Rumah Sakit Umum Daerah Mangusada Kabupaten Badung. STIKES Bina Usada Bali.

13. Dinas Kesehatan Provinsi Bali. (2017). Profil Kesehatan Provinsi Bali Tahun 2017. Bali. Retrieved from https://www.diskes.baliprov.go.id/profilkesehatan-provinsi-bali/

14. Ghassani, Z., \& Firmawati, E. (2016). Pengaruh Pemberian Aromaterapi Lavender dan Teknik 


\section{Vol. 16 No.2 Mei - Agustus 2021}

Relaksasi Nafas Dalam Terhadap SkalaNyeri pada Pasien Post Operasi Fraktur Ekstremitas di RS PKUMuhammadiyah Gamping. Yogyakarta: Universitas Muhammadiyah Yogyakarta.

15. Haryono, R. (2012). Keperawatan Medikal Bedah Sistem Pencernaan. Yogyakarta: Gosyen Publishing.

16. Indriati, M., Triwidiyantari, D., \& Apriyanti, K. N. (2018). Pengaruh Teknik Relaksasi Nafas dalam Terhadap Penurunan Intensitas Nyeri Post Sectio Caesarea di RSUD Cianjur. Sehat Masada, 12(2), 184-191.

17. Kementerian Kesehatan Republik Indonesia. (2010). Profil Kesehatan Indonesia. Jakarta: Departemen Kesehatan.

18. Laila, N. N. (2011). Buku Pintar Menstruasi. Yogyakarta: Buku Biru.

19. Netherfield. (2018). Applications of Lavender Oil. Retrieved March 28, 2020, from Lavender Uses website: https://www.netherfield.co.nz/lavenderuses.php

20. Noffsinger, A. E. (2017). Fenoglio-preiser's gastrointestinal pathology, fourth edition. In Fenoglio-Preisers Gastrointestinal Pathology, Fourth Edition.

21. Nugroho, T. (2011). Asuhan Keperawatan Maternitas, Anak, Bedah Dan Paenyakit Dalam. Yogyakarta: Nuha Medika.

22. Potter, P., \& Perry, A. (2010). Fundamental Of Nursing: Consep, Proses and Practice (7th ed.). Jakarta: EGC.

23. Rahmawati, I., \& Rohmayanti, R. (2015). Efektivitas Aromaterapi Lavender Dan
Aromaterapi Lemon Terhadap Intensitas Nyeri Post Sectio Caesarea (Sc) Di Rumah Sakit Budi Rahayu Kota Magelang. Journal of Holistic Nursing Science, 2(2), 10-16.

24. Sari, D. P., Rufaida, Z., \& Lestari, S. W. P. (2018). Nyeri persalinan (pp. 1-30). pp. 1-30. E-Book Penerbit STIKes Majapahit.

25. Seifi, Z., Bikmoradi, A., Bazrafshan, M.-R., Poorolajal, J., Araghchian, M., Kashfi, S. H., ... Jokar, M. (2018). The Effect of Inhalation Aromatherapy with Lavender Essential oil on Pain Severity of Patients After Coronary Artery Bypass Surgery: A Single-blind Randomised Clinical Trial. Journal of Clinical and Diagnostic Research, 12(7).

26. Sjamsuhidajat, R. (2012). Buku Ajar Ilmu Bedah (Ketiga; reno R. Sjamsuhidajat, Karnadiharjo, Warko, Rudiman, Ed.). Jakarta: EGC.

27. Smeltzer, \& Bare. (2012). Buku Ajar Keperawatan Medikal Bedah Brunner dan. Suddarth (8th ed.). Jakarta: EGC.

28. Utami, S. (2016). Efektifitas Relaksasi Napas dalam dan Distraksi dengan Latihan 5 Jari Terhadap Nyeri Post Laparatomi. Jurnal Keperawatan Jiwa, 61-73.

29. Widayani, W. (2017). Aromaterapi Lavender dapat Menurunkan Intensitas Nyeri Perineum pada Ibu Post Partum. Jurnal Ners Dan Kebidanan Indonesia, 4(3).

30. World Health Organization. (2018). Global Health Estimates 2016: Deaths by Cause, Age, Sex, by Country and by Region, 2000-2016. Geneva. In World Health Organization. 